\title{
The consequences of the electronic trading and eFulfillment services development on human resources
}

\author{
C Isac $^{3}$ \\ ${ }^{1}$ Faculty of Science, University of Petrosani, Romania \\ E-mail: isacclaudia@gmail.com
}

\begin{abstract}
A actualy distribution system in electronic commerce is the e-Fulfillment. In the first part of the paper by presenting the concept and technological developments we have highlighted several classifications thereof. The biggest part presents the main operations are conducted at the operator e-Fulfillment, from taking products from suppliers, management, logistics, comparative analysis of classical storage and eFulfillment systems, some aspects of the advantages of using these systems, the costs involved and examples for Romania. The paper ends with some aspects of the consequences of the electronic trading and eFulfillment services development on human resources.
\end{abstract}

Keywords: eFulfillment, distribution system, technological developments, online operators

\section{Introduction}

Currently, information technologies, where the Internet is the point of reference, are present in all fields of activity of the contemporary man and the generalization of electronic exchanges of information has determined the universal character of interpersonal and business communication. Due to the changes in the way of shopping worldwide, the trade has gone from the direct contact between people to being done through intangible means and a variety of alternatives, offered according to the needs of the customer to obtain goods. E-commerce is the basic element or piece of the new economy, and the Internet is the main medium through which it makes its presence felt.

Although e-commerce has changed the nature of global trade, it is developing at different rates worldwide [7] and has a significant impact on businesses and the business environment seen as a whole. As the number of Internet users grows, experts believe that e-commerce will soon become the main means of affecting transactions [1].

E-commerce has grown rapidly over time and more and more organizations are generating these channels of communication with the customer to enhance business relationships [3]. As a result, organizations that have offered products through traditional channels, find better alternatives to make nice profits through virtual channels corroborated with increasingly modern forms of storage and distribution. 


\section{Efulfillment research}

Currently, online store administrators have the opportunity to outsource inventory management, ordering, billing, packing and parcel delivery through e-Fulfillment services. Therefore, starting from the operating mode, e-Fulfillment can be defined as a logistic service addressed to online stores for taking over their operations [2].

The first in-depth research on fulfilment strategies was published by Mather (1988), where he discusses the relationship between production time $\mathrm{P}$, that is, how long it takes to manufacture a product and time to complete demand $\mathrm{C}$. Their sum represents the time that customers is willing to wait for the execution of the order, from the request addressed to the point of sale to the delivery of the product to the customer. Sometimes order fulfilment is used to more accurately describe the distribution act or logistics function, but in a broad sense it refers to how companies respond to customer orders.

Currently, all companies are trying to permanently reduce this time, reducing being often considered a competitive advantage in front of competitors. In this context the operationalization of eFulfilment is a necessity and an advantage. E-fulfillment is the service by which an operator takes over the entire process of order fulfilment on behalf of an online store, from storage, to taking orders, packing and delivery or even website management, based on cloud management, reporting and order tracking. Basically, the order fulfilment time is greatly reduced by taking the goods on the efulfillment platform.

In other words, e-fulfillment means the sum of the logistical processes by which a product ordered in an online store is packaged and delivered to the courier for delivery to the consumer.

Considering the gradual increase of e-commerce sales and the increased interest for omni-channel (OC) e-Fulfillment trading, it is a powerful logistics system [5] and which allows the implementation of efficient and quality services [4].

As for the benefits of implementing the eFulfillment system, they delimit a new stage in the development of e-commerce and the transition from traditional online merchants to those who implement a logistics system of "inventory matching on demand" [8].

Thus, the main advantages for companies that use eFulfillment systems can be analysed from the perspective of the relationship between consumers and online operators and refers to: a more direct and beneficial relationship with producers; high expectations for conventional producers and retailers regarding the implementation of development strategies; reducing costs on the distribution chain, by reducing transport, handling and even management and packaging services; achieving a balance between the manufacturer and the online retailer; maintaining a more distant consumer position with regard to retailers, lower prices for consumers; much easier identification of suppliers and business partners etc.

\section{Comparative analysis of classical storage and eFulfillment systems}

Since 2000, Delphi Group has identified a new trend regarding the emergence of new types of intermediaries in the electronic commerce, intermediaries who take over most of the activities carried out in an electronic store and a concentration of the activity of several owners towards a single distributor.

The advantages of the eFulfillment system change the traditional warehouse that has been declining in recent decades by the gradual introduction of Just In Time (JIT), which involves automated work processes, so that a drastic reduction of the human resource inside the classic warehouses takes place. In addition, sales and operating decisions are increasingly closely linked, as delivery and after-sales services become key components of the product offering [6].

Moreover, through these systems some warehouses are without workers, fully automated. Pallets and products are handled with a system of automated conveyors and automated storage and with the 
help of recovery machines coordinated by programmable logic drivers and by computers with logistics software.

Due to the development of e-commerce and the direct or indirect influences of eFulfillment services, several consequences can be delimited that affect the workforce of these companies:

- reducing errors, in general and human errors, in particular, through the automation of work processes, following the increasing introduction of information and communication technologies;

- improves the systems by using ERP system modules that work integrated through the use of a common database and which involve highly qualified employees;

- change of occupations, some disappear and new ones appear (statistician, soft worker, etc.);

- the use by managers of solutions / applications based on interactivity, support in decision making, use of organizational memory to capitalize information and knowledge etc. They allow considerable improvement of the management process and the responsibilities in the job description;

- in fact, the use of ICT leads to a true effect of organizational coherence (coherence between the organizational structure and the decision-making structure). The Internet determines the organizations to reconsider the coordination mechanisms (communication and control). ICT also influences the elements related to structure (organization). Processes and relationships are reanalysed and structured so as to streamline information flows and ensure seamless communication between employees (information is provided at the right time and the person who needs it);

- the introduction of automated technologies allows the reconfiguration of the spaces in a company with eFulfillment services and the replacement of the employees mostly with the systems of product identification, take over the tape and their packaging and labelling;

- use of systems in low temperature warehouses to prevent products from deteriorating and which allow the protection of human health.

The e-fulfillment service presents many advantages, especially for e-commerce start-ups due to the fact that it provides them with flexibility and fast scalability in the storage, management, take-up and delivery of their products, while being a simple solution, immediately implementable, of which the main advantage is that it turns a fixed cost into a variable one.

Table 1. e- Fulfillment advantages.

\section{Type of advantage offered through eFulfilment The effects of the beneficiary of eFulfillment services}

1 Taking over of storage operations, taking orders, managing goods, invoicing, packing, delivery.

2 Transformation of indirect costs into direct costs in proportion to the number of orders delivered and stored the volume of goods.

3 The owners of online stores can focus exclusively on business development, increasing the portfolio of commercialized products, promoting and strategically positioning them on the market.

4 Track the activities undertaken by the eFulfillment cloud by ERP and Business Intelligence, which allows you to view a dashboard at the end of the day or in real time.

5 Achieving minimum shipping times, guaranteeing well-packaged items, consistent delivery and an easy return process. (as is the case with eMag).
External storage, order taking, asset management, billing, packing, delivery. Reducing the functioning of the expenses with the electronic store.

Focusing on product portfolio development, increasing competitiveness and promoting them.

Visualization, supervision and control of outsourced services.

Creating a competitive advantage by increasing the efficiency of deliveries 


\section{The influence of eFulfilment operational processes on the workforce}

In the figure below it is presented in the form of a diagram, the use of ICT that causes major changes in terms of strategy, structures, management processes, but also the role of the people, respectively of the human resources within the companies that offer e-fulfillment services.

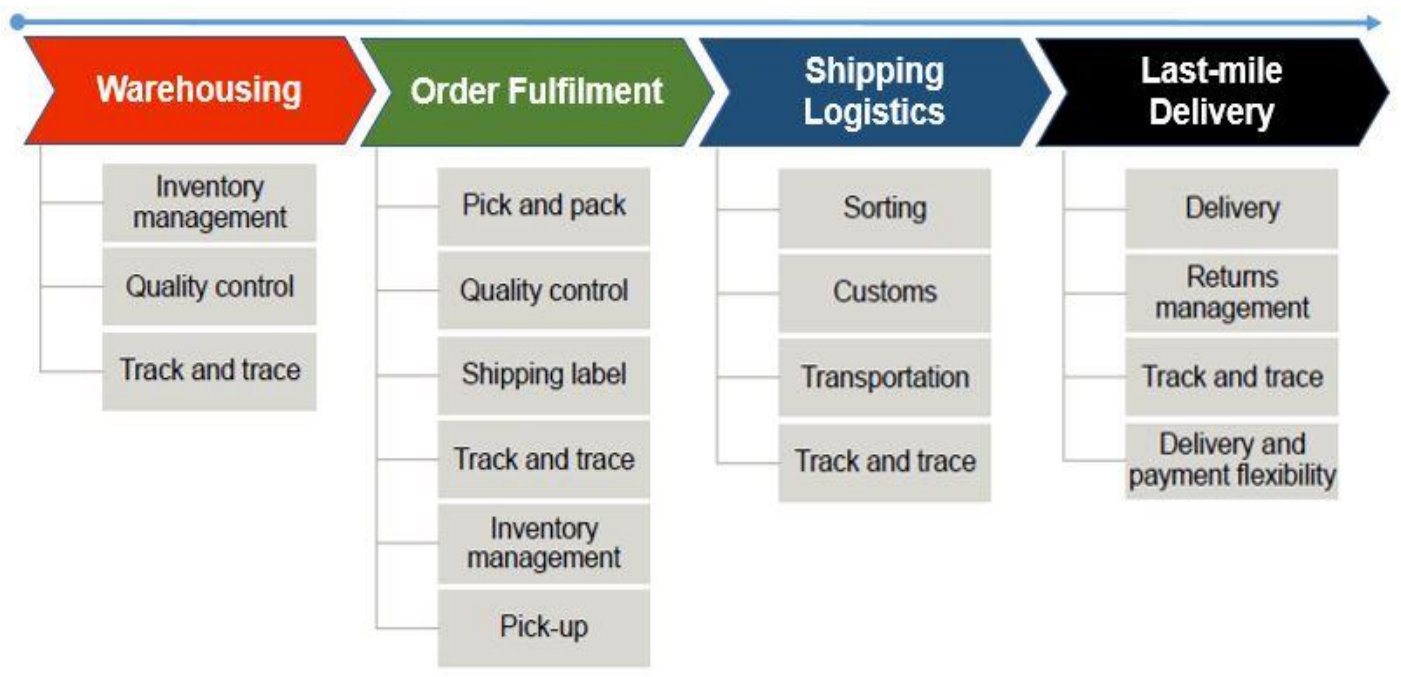

Figure 1. Elements of the eFulfillment operational process.

The presence of logistics platforms with automated elements of the distribution system in which operations are carried out for transhipment of goods, warehousing, marketing of bulk goods, packing, sorting and grouping of goods for their shipment reconfigure the need to prepare employees, so that they are registered a shift from the use of the unskilled labour force to the specialized workforce and preferably with higher education. ${ }^{1}$

In other words, it creates an influence on the workforce that results into different norms of work, the number of employees is decreasing, but instead, the automation is increasing.

To highlight the main problems faced by distribution centres, the results of a survey conducted in 2017 by the research company Aberdeen Group Inc are shown in figure 2 .

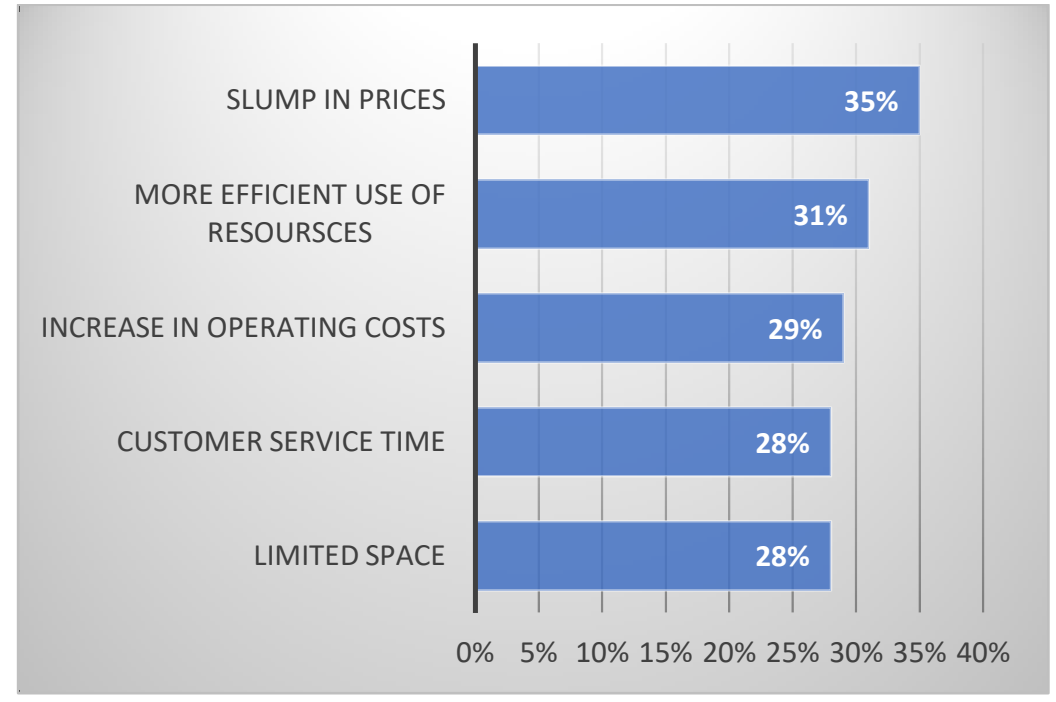

Figure 2. Results of the survey on the problems of distribution centres Source: processing by Senior software Good practices in warehouse management 
The survey was conducted on a sample of 159 international companies that have distribution centres. The problems mentioned in the graph above are known to the logistics specialists and their solution is gradually solved by introducing WMS-type systems that automate and optimize the activities of reception, storage, collection and dispatch of the goods, offering permanently real-time information on the status of the stocks, of the storage space, allows the packaging, inventory or resupply. The integration of these systems allows the visibility of the stock in all channels and distribution locations, optimizing the flow of goods and satisfying the multi-channel demand. From a financial point of view, the wage expenses with the labour force from the warehouses register a substantial pressure on the operational costs, with weights of up to $45 \%$, which amplifies the need to adopt the e-Fulfillment systems.

In conclusion, the appearance of e-fulfillment deposits, as compared to the classic deposits, has produced changes in the work force as follows: the emergence of new occupations such as pickers, the reduction of the number of personnel and of the expenses with the payment of the salaries due to them.

\section{Conclusions}

E-commerce confirms the role of information and communication technologies in enhancing the competitive potential of an enterprise and ensures its complex development prospects. In this context, the e-fulfillment service represents an opportunity through the multiple advantages that it offers materialized in reducing costs and transforming fixed costs into variable costs, flexibility and speed in the storage, management, take-over and delivery of goods.

\section{References}

[1] Dobre-Baron O. 2010, Economia comerţului, Editura Universitas, Petroşani

[2] Isac C., Managementul afacerilor electronice, Ed. Universitas, Petroșani, 2018, pp 52-84

[3] Hu X. 2016 , Research on the impact of B2C e-commerce and third party platform: An empirical analysis based on factor analysis, International Journal of Smart Home, vol. 10, no. 3, pp. 315-324

[4] Kumbhar V. 2012, Conceptualization of e-services quality and e-satisfaction: a review of literature, Management Research and Practice, vol.4

[5] Melacini, M., Perotti, S., Rasini, M. and Tappia, E. 2018, "E-fulfilment and distribution in omni-channel retailing: a systematic literature review", International Journal of Physical Distribution \& Logistics Management, Vol. 48 No. 4, pp. 391-414

[6] Niels A.H., Agatz M., FleischmannJo A.E.E.van Nunen, 2008, E-fulfillment and multi-channel distribution - Areview, European Joumal of Operational Research, Volume 187, Issue 2, pages 339-356

[7] Zheng H., 2016, A study on the usability of e-commerce websites between China and Thailand, International Journal of Simulation: Systems, Science and Technology, vol.17, no. 1, pp. 341-344

[8] Woudhuysen J., 2001, E-fulfillment: The opportunities for the future, Interactive Marketing, January 2001, Volume 2, Issue 3, pp 219-229

[9] http://www.sciencedirect.com/science/article/pii/S0377221707004195

[10] http://fulfillmentwarehouse.com/ecommerce-fulfillment-services

[11] http://www.fulfillmentcorp.com/

[12] http://www.dhl.com/en/logistics/supply_chain_solutions/what_we_dole-fulfillmenthtml\#.VIBF7mflJkM

[13] http://www.erdtconcepts.com/order-fulfillment-logistics-shipping-services-for-your-e-commerce.html

[14] http://documentation.ektron.com/cms400/v85/mobile_help/advanced/content/eCommerce /Feature\%200verview/order fulfillment.htm

[15] http://www.scdigest.com/ontarget/13-08-20-1.php?cid=7328

[16] http://www.slideshare.net/codyringojake/e-fulfillment-trends-report-2011-copy

[17] http://www.efulfillmentservice.com/ebay-fulfillment/

[18] http://www.logwin-efulfillment.com/

[19] http://ingtrans.pub.ro/wp-content/uploads/2017/07/LUCRARI/2007/2..pdf 